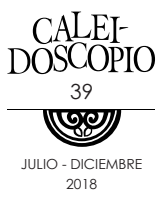

\title{
Jóvenes, trabajo y emancipación: llaga neoliberal de nuestro tiempo
}

Youth, work and emancipation: neoliberal wound of our time

OLGA LETICIA ÁLVAREZ COOPER'

RESUMEN

En el presente ensayo analizamos el desarrollo del neoliberalismo durante el siglo xx e inicios del siglo XxI, y la relación que guarda con la emergencia de lo juvenil. Interesa comprender el vínculo existente entre el programa neoliberal y la emancipación de los jóvenes; es decir, cómo los modelos laborales del siglo xxI han impactado las trayectorias rumbo a la independencia familiar y económica que se suponía inauguraban el tránsito de la condición juvenil a la adulta. Consideramos que las fuentes elegidas ayudan a entender de manera sintética la historia evolutiva del programa neoliberal y, a la par, permiten comprender el proceso de transformación de la condición juvenil.

Palabras clave: juventud, capitalismo, neoliberalismo, emancipación.

\section{ABSTRACT}

In this essay, we analyze the development of neoliberalism through the twentieth century and the beginning of the twenty-first century, addressing its links with the emergence of youth. The aim is to understand the relation between the neoliberal program and the emancipation of young people; that is to say, how the labor models of the $21 \mathrm{st}$ century have impacted the trajectories towards family and economic independence that were supposed to inaugurate the transition from

1 Universidad Autónoma de San Luis Potosí, México. 
youth to adulthood. We consider that the chosen sources are useful to synthetically understand the evolutionary history of the neoliberal program. At the same time, they allow us to understand the process of transformation of the juvenile condition.

Keywords: youth, capitalism, neoliberalism, emancipation.

Anteriormente, la entrada de los jóvenes al mundo laboral inauguraba también su ingreso a la vida adulta. No obstante, los cambios ocurridos en la esfera del empleo (relación contractual, flexibilización de horarios, deslocalización y fragmentación de actividades productivas, etc.) a nivel global también han modificado la idea de que la inserción laboral representaba el punto de clausura de la juventud. El trabajo solía ser el medio a través del cual los jóvenes lograban emanciparse del hogar parental y alcanzaban independencia económica para, a su vez, comenzar su propio ciclo social y productivo como sujetos autónomos. Esta discordancia entre inserción laboral y condición de adulto es uno de los fenómenos medulares de las discusiones entre quienes estudian a los jóvenes.

A lo largo del siglo xx, los jóvenes irrumpieron con fuerza en el ámbito público, alterando dinámicas sociales y culturales del mundo occidental. Características distinguibles en diferentes "generaciones de jóvenes protagonistas" (Feixa, 2006: 3) se han vinculado con momentos históricos que fueron marcando cada década de ese siglo. De acuerdo con Feixa (2006), la presencia de sujetos jóvenes fue fundamental en eventos militares y revolucionarios. Se les atribuye la creación de propuestas alternativas de vida, como lo fueron los movimientos hippie y punk, e incluso se les considera iniciadores del surgimiento de tendencias musicales como el rock y el pop. Participaron en reclamos por la libertad de expresión y la paz, así como en manifestaciones que se oponían a la globalización. De igual manera, se les señala también como un segmento de consumidores de gran relevancia para los mercados globales (contenidos audiovisuales, tecnología, ropa, drogas, etcétera.).

Para los fines de este trabajo, interesa en particular centrarnos en los jóvenes de las últimas dos décadas del siglo anterior; se considera que los rasgos particulares de esos grupos de edad se han extendido a las generaciones de principios del siglo XXI. En un reporte de la Organización de las Naciones Unidas para la Educación, la Ciencia y la Cultura (Unesco), citado por Feixa (2006: 13), se contrasta la genera- 
ción de inicios de 1980 con la de 1968 para evidenciar los cambios en las motivaciones, actitudes y contextos de los jóvenes occidentales. Entre las palabras utilizadas por este reporte para describir los años sesenta se encuentran: "confrontación, protesta, marginalidad, contracultura", es decir, aparecían mensajes y actos de esperanza en la transformación social. No obstante, el pronóstico para las siguientes generaciones dibujaba un panorama adverso e incierto, marcado de manera particular por la escasez de oportunidades laborales.

La última década del siglo xx confirmó las predicciones hechas por la Unesco. A la incertidumbre y el desempleo habría de unírseles una nueva circunstancia, consecuencia del avance tecnológico: el acceso a nuevos dispositivos tecnológicos, entre ellos, las computadoras y, posteriormente, el acceso a Internet. Para millones de jóvenes contar con una computadora conectada a la red bastaba para acceder a gran cantidad de recursos de información, posibilitando además la comunicación con usuarios de cualquier parte del mundo.

Actividades de la vida diaria se vieron transformadas con la emergencia de las redes; como ejemplo de ello se puede mencionar la manera de conocer, aprender, intercambiar, expresar, sentir, comunicar, escribir, comercializar y trabajar. Lo anterior generó nuevas formas de exclusión, de protesta y también de diversión; a la par de la construcción de "comunidades virtuales [aparecieron] también nuevas soledades" (Feixa, 2006: 14), las cuales han atraído el interés científico para comprender los efectos económicos y socioculturales de las redes sociales. Integrados y conectados a través de las redes sociales, pero marginados en el ámbito escolar y laboral; así podría describirse el mundo que habitan muchos jóvenes.

No obstante que la edad cronológica, aunque insuficiente, persiste como una herramienta relevante para la delimitación y estudio de lo juvenil, parece haber consenso en que hay muchas y muy diversas formas de ser joven. Las palabras y los significados utilizados para caracterizar a las juventudes son, por lo tanto, también heterogéneos. De acuerdo con la Comisión Económica para América Latina y el Caribe (CEPAL, 2008), "la juventud aparece como un concepto poco claro en la medida que engloba bajo un mismo rótulo a un conjunto social muy heterogéneo" (p. 11). Para Levi y Schmitt (1996) existen múltiples juventudes; por consiguiente, asignar a la juventud un concepto "concreto y estable" (pp. 8-9) resulta complejo. Se le puede concebir como una condición variante y dependiente de situaciones y consideracio-

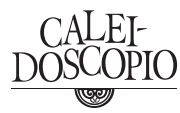


nes de carácter económico, social y cultural, que diferencian y matizan cómo se vive ser joven en sociedades plagadas de segmentaciones, ambigüedades y brechas que van moldeando imaginarios juveniles desiguales.

Se podría decir, entonces, que la juventud es un concepto dinámi$\mathrm{co}$, en permanente construcción. Los adultos han construido social y discursivamente la idea de juventud; en consecuencia, los discursos que pretenden describir las realidades cotidianas de los jóvenes son múltiples, diversos y algunas veces contradictorios (Revilla, 2001). Una de las principales finalidades de dicha construcción de la juventud ha sido la de perpetuar la reproducción de la sociedad o, en otras palabras, "asegurarse de que la reproducción social se realice adecuadamente" (Revilla, 2001: 104).

Revilla identificó y estudió diferentes producciones discursivas sobre los jóvenes con la intención de comprender "el grado de agencialidad" (2001: 106) que los adultos les conceden como sujetos históricos. Al respecto, señala que los jóvenes despliegan su capacidad de agencia en sus interacciones con otros jóvenes, pero la influencia de sus acciones es menor "en el marco de la sociedad global" (p. 106). Entre los diferentes discursos analizados por Revilla están el narcisismo y la mitificación de lo juvenil, rebeldías y subculturas juveniles, transición a la vida adulta, discriminación, identidad, diversidad y la juventud vista más como un producto social que como un verdadero agente de cambio. De acuerdo con el planteamiento del autor, son los jóvenes quienes están más abiertos y cercanos a los cambios; esto explicaría por qué les resulta más fácil incorporarlos en sus vidas. Tal vez por eso se les percibe como innovadores y creativos. Al respecto, los investigadores de la CEPAL (2008) reflexionan sobre el hecho de que a los jóvenes se les conciba como "portadores del cambio, con mayor autonomía moral que los niños, pero sin la autonomía material de los adultos" (p. 10).

Sobre el tema particular de la transición a la vida adulta, como se ha visto, el discurso tradicional considera que la adultez libera a los jóvenes de su condición juvenil al brindarles la posibilidad de emanciparse del hogar parental, ser autónomos e independientes financieramente, incluyendo la oportunidad de formar su propia familia. Al respecto, la CEPAL (2008) establece que "la autonomía suele atribuirse casi como un valor natural de la juventud; sin embargo, no es tan fácil de construir como proyecto efectivo de vida, dadas las barreras al 
empleo y la vivienda" (p. 11). De acuerdo con esto, conseguir trabajo remunerado no asegura poder independizarse completamente de los padres. Hay personas que han rebasado la edad juvenil convencional, pero no "han alcanzado plenamente el estatus de adulto" (Revilla, 2001: 118). Lo anterior diversifica los trayectos rumbo a la vida adulta que vuelven relevante seguir indagando sobre este tema de la emancipación juvenil ligado estrechamente al trabajo.

Para profundizar sobre la relación trabajo y emancipación juvenil, Verd y López-Andreu (2016) estudiaron trayectorias laborales en adultos jóvenes menores de 40 años, población "protagonista del empleo temporal" (p. 7) y con mayor susceptibilidad al detrimento de las condiciones laborales en España. Estos autores muestran que la polarización del empleo, paradójicamente, consecuencia de políticas públicas implementadas para corregir problemáticas económicas, como la del desempleo, ha favorecido la aparición de "itinerarios de inserción laboral precaria" (p. 11). Por lo tanto, el fenómeno de la juventud retenida puede atribuirse a trayectorias divergentes e inseguras vinculadas al mundo laboral actual. Tales condiciones contribuyen a que el "efecto cicatriz" (p. 12)-consecuencia de políticas orientadas a corregir desequilibrios macroeconómicos- genere "procesos de acumulación de desventajas" (p. 12) en las biografías de los jóvenes.

El diagnóstico elaborado por la CEPAL y la Organización Iberoamericana de Juventud (CEPAL y OIJ, 2007) subraya la ambigüedad observada en los jóvenes respecto a su capacidad de participación social y ciudadana. Por un lado, se ve a "la juventud [como] un actor de gran creatividad cultural" (p. 20); pero, a pesar de tener buena disposición para los cambios, este grupo poblacional poco incide en ellos. Por otra parte, el estudio agrega que "si hace tres o cuatro décadas los jóvenes se redefinieron como protagonistas de la épica del cambio social, hoy la juventud se redefine, en la esfera del discurso público, como objeto de políticas sociales y sujeto de derechos" (p. 20); esto quiere decir que, en general, los jóvenes se identifican más como sujetos merecedores de derechos y ciertos privilegios, y no se perciben a sí mismos como agentes de cambio.

Por otro lado, como parte de este debate, García Canclini considera injusto etiquetar de apáticos o indiferentes a todos los jóvenes. Por ello, insiste en reconocer cómo el modelo económico los excluye, por tanto, declara necesario repensar a los jóvenes y a partir de ello revitalizar políticas y estrategias públicas sintonizándolas

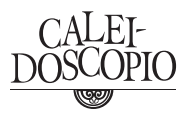


con "los modos emergentes de sociabilidad y creatividad" (García y Piedras, 2013: 19) observados en ciertos segmentos de sujetos jóvenes. A su vez, Gómez (2012) concluye que la precariedad provoca en ciertos jóvenes reacciones de "desafío y rebeldía" (p. 32).

\section{LA LLAGA NEOLIBERAL}

Aunque se le vincula casi de manera automática con la esfera económica, el neoliberalismo trasciende las fronteras de esa disciplina. Es un programa intelectual, ${ }^{2}$ cuya influencia se extiende a otros ámbitos de la vida humana. El neoliberalismo, considerado como "la ideología más exitosa" (Escalante, 2015: 23) que prevalece en la actualidad, surge en la segunda mitad del siglo xx y se sostiene en tres ideas fundamentales: busca reclutar al Estado ${ }^{3}$ como colaborador de su proyecto; supone que el mercado es el único medio para lograr tanto el bienestar social como la libertad del individuo; y, por último, afirma que el sector privado es superior y más eficiente que el público. A este conjunto de ideas insignia del programa neoliberal le bastó menos de tres décadas para convertirse "en un movimiento global que consiguió transformar el horizonte cultural del mundo entero" (p. 23). Para Dallanegra (2015), "la configuración del sistema mundial y el proceso histórico de globalización han sido la resultante de la expansión y la dominación económico-comercial, militar, político-ideológica, cultural y religiosa" (p. 19). Una dominación liderada históricamente por un puño de países occidentales, quienes han marcado las normas de comportamiento para el resto de los países. El resultado ha sido un mundo complejo basado en un modelo de culturas que dominan y otras que sobreviven.

Se puede llamar "momento liberal" (Escalante, 2015: 19) al recorrido que ha tenido el liberalismo hasta llegar a su situación presente. Sus inicios se remontan a la época de la Ilustración en el siglo XVIII. Aquellos años atestiguaron las revoluciones acontecidas en Francia

2 De acuerdo con Escalante (2015: 17), el neoliberalismo "es un programa intelectual, un conjunto de ideas acerca de la sociedad, la economía, el derecho, y es un programa político, derivado de esas ideas".

3 Contrario a lo que se cree, el programa neoliberal "no pretende eliminar al Estado, ni reducirlo a su mínima expresión, sino transformarlo, de modo que sirva para sostener y expandir la lógica del mercado" (Escalante, 2015: 21). 
y Estados Unidos, y los procesos de independencia de las Colonias Americanas. El momento cúspide liberal lo podemos ubicar en el intermedio del siglo XIX. Esta etapa se distinguió por el florecer de los derechos políticos y civiles. Los pueblos occidentales fueron incorporando en sus imaginarios la idea de libertad que germinó en el ánimo de la gente. La tensión generada más tarde por las movilizaciones obreras y la aparición de diversas formas de socialismo comprometieron el brillo alcanzado por el liberalismo. Los brotes de resistencia obrera, opuestos al sistema hegemónico, la crisis financiera de 1929 y las consecuencias de los conflictos bélicos de repercusión mundial, obligaron cambios en la estrategia. Podríamos decir que las libertades ganadas a partir del proceso liberal se fueron transformando en nuevas posturas que confrontarían al propio sistema.

El proyecto ideológico enunciado arriba ha logrado llevarse a la práctica mediante las siguientes líneas de acción emprendidas, trabajando en equipo con el Estado: "Privatización de activos públicos: empresas, tierras, servicios; liberalización del comercio internacional; liberalización del mercado financiero y del movimiento global de capitales; introducción de mecanismos de mercado o criterios empresariales para hacer más eficientes los servicios públicos; y un impulso sistemático hacia la reducción de impuestos y la reducción del gasto público, del déficit, de la inflación" (Escalante, 2015: 22-23).

\section{ANTECEDENTES DEL NEOLIBERALISMO}

El Consenso de Washington (CW) es un conjunto de políticas sugeridas con carácter mandatorio, establecidas por los Estados Unidos (EU) a los países que por las propias características de su proceso de desarrollo, se han visto en la necesidad de recurrir al financiamiento externo. Tales recursos financieros son entregados a los países, envueltos en un paquete económico que, junto con el dinero, lleva implícito condiciones y compromisos que habrán de cumplirse junto con el pago de la deuda. Como lo aseguran Martínez y Soto (2012), "sus políticas siguen vigentes y son las más influyentes en las economías de muchos países de América Latina, gracias a que éstas forman parte de las condiciones que los organismos internacionales imponen a sus países miembros, principalmente cuando éstos necesitan préstamos" (p. 35).

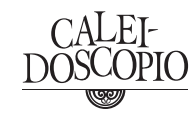


Los antecedentes del cw fueron los acuerdos Bretton Woods de mediados del siglo pasado, los cuales cimentaron su estrategia sobre tres ejes: "desarrollo, estabilidad financiera internacional y liberalización del comercio" (Martínez y Soto, 2012: 36). Posterior a la Segunda Guerra Mundial, Eu se posiciona como el principal acreedor de los países involucrados en el conflicto bélico, lo que derivó en un incremento significativo en la acumulación de capital de este país de América del Norte. A partir de esta inercia, se crean "organismos internacionales encargados de presentar propuestas de políticas económicas encaminadas a impulsar el crecimiento económico y resolver problemas más apremiantes originados en las recesiones" (p. 37). En otras palabras, se pretendían resolver dificultades económicas por medio del financiamiento de proyectos orientados a promover el progreso y aminorar la pobreza de los países. El organismo primogénito fue el Banco Mundial (BM). Posteriormente nació el Fondo Monetario Internacional (FMI), ambos con sede en Washington.

Al final del día, es posible mirar al cw como un mecanismo concebido para transitar de un "modelo económico cerrado a uno abierto y liberalizado" (Martínez y Soto, 2012: 63), pero principalmente para detentar el control político y económico de los países deudores. Al respecto, los autores concluyen que el cw "se convirtió en una especie de ideologización económica para América Latina, las políticas económicas dejaron de ser simples propuestas y pasaron a ser un instrumento de control político y económico para los países interesados en insertarse y conseguir el sello de aprobación de las economías altamente desarrolladas y de los organismos internacionales" (p. 64).

Los cambios en la ruta del liberalismo se reflejaron en el renovado protagonismo que adquirió el Estado; quien adquirió un rol bienestarista incorporado en sus políticas económicas, traducido en incrementos significativos al gasto social como acción inmediata para la recuperación. Ello se tradujo en mejoras en los servicios públicos, seguridad social y creación de fuentes de empleo. La recaudación fiscal se intensificó mediante un esquema tributario progresivo. El papel asumido por el Estado no fue bienvenido en todos los frentes. Ahora son los dueños del capital quienes se oponen; pugnan por el retorno de la supremacía del mercado como brújula económica de las sociedades. Ello requirió la emergencia del individualismo como la identidad idónea de los nuevos tiempos, junto con la degradación del Estado a un puesto subordinado al servicio del capital. Lo anterior dotó de diferentes ras- 
gos al liberalismo original hasta culminar en el programa neoliberal que predomina actualmente.

A continuación, se resume los que pudieran considerarse como los siete mandamientos del proyecto neoliberal: 1) el mercado es la única vía posible para lograr el bienestar, la eficiencia, el buen gobierno; es la materialización de la libertad individual; 2) se requiere un Estado fuerte, pero aliado y dispuesto a colaborar; es un actor imprescindible para consolidar el proyecto libertador que ofrece el mercado; 3) las deficiencias del sector público se resuelven privatizando; 4) el individuo es un ente racional y competitivo; el sentido de su vida radica en la persecución continua de intereses subjetivos y la maximización de beneficios personales; 5) la política es un mercado más y ha de funcionar como tal; 6) el mercado tiene poderes regenerativos y auto sanadores: es capaz de corregir los problemas que ocasiona; y 7) la desigualdad no sólo es inevitable, es un factor indispensable para el bienestar económico, por lo que hay que preservarla y, de ser posible, acrecentarla (Escalante, 2015).

En la actualidad, la tecnología, la capacidad de innovación aplicada y la competitividad son los factores que distinguen a una nación dominadora de una dominada. En otras palabras, son los "factores de poder" (Escalante, 2015: 20) de los actores internacionales. Actores que han sumado fuerzas involucrándose en procesos de integración que tienen como fin primordial "controlar los recursos naturales estratégicos" (p. 20), y así asegurar, ya sea su permanencia privilegiada en el sistema mundial o fortalecer su posición ante quienes detentan tales privilegios, es decir, "los que están arriba tienden a mantener el statu quo; los que están abajo buscan diferentes metodologías para cambiar el sistema en beneficio de su mejor inserción" (p. 38). En este último caso, la sociedad civil, que suele conformarse o representar los intereses de "los de abajo", ha comenzado a "emerger como un actor significativo, aunque no con el poder suficiente como para generar reglas del juego tan relevantes como las empresas y la banca en el contexto mundial global" (p. 21).

INSEGURIDAD Y PRECARIEDAD LABORAL: RESIDUOS NEOLIBERALES

De acuerdo con Castel (2008), "la exigencia de vencer la inseguridad civil y la inseguridad social está en el origen del pacto que funda una

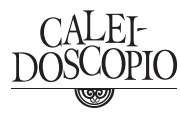


sociedad de individuos" (p. 115); es decir, es inherente a la evolución de la sociedad, una sociedad que busca el bienestar de los individuos que la integran. El desarrollo histórico de los dispositivos de protección ha sido paralelo a otros procesos, como el avance de la democracia y la transformación del Estado (p. 113). Este autor considera que, en los países desarrollados de Occidente, las condiciones de vida del siglo XXI superan por mucho a las que existían en épocas anteriores, en las que grandes segmentos de la población se veían obligados a vivir "al día" (p. 11). Esto significa que la incertidumbre sobre el porvenir era tal, que les resultaba casi imposible hacer planes a futuro. Cabe mencionar que esta última situación es uno de los rasgos vigentes de las trayectorias laborales de países como México. La incertidumbre o, mejor dicho, las condiciones de los trabajos del pasado parecieran haber retornado para instalarse en los entornos laborales globales.

A pesar de que, en general, las sociedades occidentales cuentan con protecciones civiles y sociales -conquistadas en su mayoría por las luchas sociales acaecidas en los dos siglos anteriores-, la preocupación por la inseguridad no se ha erradicado (Castel, 2008: 12). Según el autor, esta preocupación se inscribe en la realidad y configura la "experiencia social" (p. 812) de los individuos. Es decir, es uno de los factores que determina la experiencia vital de los integrantes de una sociedad. Con su trabajo, Castel denuncia lo que él llama "la inflación de la preocupación por la seguridad" pero, a la vez, ratifica "la importancia esencial de la necesidad de protecciones" (2008: 114).

Para este mismo autor, "la seguridad jamás está dada" (2008: 15), la consecución de protecciones genera objetivos inéditos, surgiendo entonces nuevas búsquedas para satisfacer las demandas recién concebidas. Así, el ciclo de necesidades se autoreproduce y la sensación de inseguridad perdura. Castel atribuye la inseguridad moderna, no tanto a la disminución de protecciones, sino a la "búsqueda sin fin de protecciones o de una búsqueda desenfrenada de seguridad" ( $\mathrm{p}$. 12); es decir, concibe una sociedad atrapada en un bucle impulsado por la búsqueda utópica de la seguridad eterna. Se podría decir que es una sociedad protegida, pero, al mismo tiempo, hiperafligida por la incertidumbre inherente a la existencia humana. Argumenta que "la propia búsqueda de protecciones estaría creando inseguridad" (p. 13). Afirma que esa necesidad continua de protecciones pudiera derivarse de la fragilidad y complejidad que los sistemas protectores creados por la humanidad han manifestado en las últimas décadas, donde el 
riesgo de fracaso en su objetivo protector ha provocado decepción y desconfianza generalizada en tales sistemas

Castel (2008) piensa que, en la actualidad, "estar protegido es también estar amenazado" (p.13). Para él, las sociedades contemporáneas promueven y extraen provecho tanto del individualismo como de la vulnerabilidad; además, dichas sociedades están conformadas por individuos incapaces de garantizar su protección total. Esta situación lo lleva a afirmar que las sociedades modernas se han cimentado "sobre el terreno fértil de la inseguridad" (p. 13); son sociedades que habitan entornos donde aún sobreviven certezas civiles y sociales, pero conviven a diario con la sensación de desprotección y fragilidad. Las diversas percepciones y deseos de "estar amparado contra todas las incertidumbres de la existencia" (p. 113) han sido aprovechadas por el mercado para ofertar al público un catálogo variado de promesas e ilusiones protectoras ( $v$. gr. proliferación en la oferta de seguros de vida, de gastos médicos, protección de bienes, educación de los hijos, seguros contra robo de equipaje y de efectivo en los cajeros bancarios automáticos, planes de ahorro para la vejez, etcétera).

En ese sentido, Castel (2008) advierte que "la ideología de la prevención generalizada está condenada al fracaso" (pp. 114-115), debido a la naturaleza limitada y falible de los mecanismos de protección, y lo imprevisible de las contingencias. La intención de eliminar las circunstancias que amenazan al bienestar "nutre una forma de angustia probablemente específica de la modernidad, y que es inextinguible" (p. 115). Por lo tanto, y tomando como base la lógica de Castel, podemos afirmar que la exagerada preocupación por la seguridad es una de las características distintivas de la etapa moderna extendida hasta la posmodernidad.

La inseguridad anclada en el imaginario social tiene que ver menos con las amenazas reales que ponen en riesgo a los individuos. La sensación de inseguridad corresponde más al "efecto de un desfase entre expectativas socialmente construida [sic] de protecciones" (Castel, 2008: 13) y la ineficiencia de los sistemas instaurados para suministrar las certezas esperadas. También afirma que "vivir en la inseguridad día a día es ya no poder hacer sociedad con sus semejantes y habitar un entorno bajo el signo de la amenaza y no de la acogida y el intercambio" (p. 115). Podemos concluir, entonces, que las expectativas no se corresponden más con la eficacia de los mecanismos protectores sociales; de ahí la necesidad latente de diseñar nuevas estrategias o

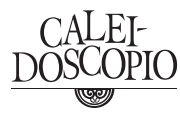


dispositivos de seguridad acordes a los desafíos que enfrentan las sociedades actuales consternadas por la "inseguridad cotidiana" (p. 115).

Aunque critica la idea de tranquilidad total dependiente del riesgo nulo o de la certidumbre absoluta, Castel sostiene que es legítimo buscar protección y anhelar condiciones de seguridad. Para este autor, "la seguridad debería formar parte de los derechos sociales en la medida en que la inseguridad constituye una falta grave al pacto social" (2008: 115). Por consiguiente, el reclamo de seguridad juega un papel clave para el posterior diseño de acciones efectivas que permitan "hacer frente del modo más realista a las inseguridades" (p. 15). Para ello, recomienda primero atender y remediar las situaciones causantes de las inseguridades civiles y sociales de las poblaciones occidentales contemporáneas (desigualdad, pobreza, violencias, desempleo, etc.); restituir todo aquello que ha roto dicho pacto social. Enmendar los factores causales de la erosión de las conquistas sociales de antaño tal vez no provea "la seguridad de estar liberados de todos los peligros, pero se podría ganar la oportunidad de habitar un mundo menos injusto y más humano (p. 15)". Aquí la función del Estado es fundamental.

El Estado debe garantizar que todos los "individuos dispongan, por derecho, de las condiciones sociales mínimas de su independencia" (Castel, 2008: 117). Entonces, el objetivo no es eliminar de forma absoluta el peligro de las biografías de los individuos, sino algo mucho más concreto: asegurar que todos los individuos tengan a su alcance las posibilidades y herramientas para emprender su emancipación.

Desafortunadamente, como se ha visto con Escalante (2015) y Contreras (2015): quien ha atinado en atender con mayor celeridad la necesidad de emancipación individual no ha sido el Estado, sino el mercado. A través de la figura del emprendedor y el autoempleo, el mercado aproxima a cada individuo la posibilidad de independencia e insubordinación. Una emancipación con estilo empresarial que tal vez libera de ciertas ataduras/restricciones ( $v$. gr. jornadas y lugares de trabajo convencionales), pero con frecuencia se logra a cambio de un alto costo: el de la inseguridad social. Ello favorece la perpetuidad de la desprotección (subcontratación, informalidad, disminución o supresión de prestaciones, alta en sistemas de seguridad social con salarios menores a los reales, descarte de la antigüedad laboral, ausencia de ahorro para la vivienda y para el retiro en la vejez, vulnerabilidad ante enfermedades y accidentes, dificultad para hacer planes a futuro -formar una familia, construir un patrimonio- etc.). En consecuencia, la 
incapacidad del Estado de generar las condiciones para que toda la población acceda a su independencia, propiciaría el ensanchamiento de las fisuras del pacto social y, por lo tanto, la sociedad se acercaría cada vez más a la frontera que la separa de la decadencia social.

Una sociedad de semejantes (Castel, 2008: 117), donde todos los individuos cuenten con los recursos suficientes y los derechos básicos para "mantener relaciones de interdependencia" (p. 117), sería la meta de la protección social. Lo anterior requeriría todo un sistema que coadyuvara en la formación de ciudadanos con una profunda conciencia social.

Castel atribuye a la sociedad salarial la construcción del "edificio de protecciones" del siglo xx. Estructura que, de acuerdo con el autor, fue desmoronándose durante las tres últimas décadas de ese siglo, como resultado de "la hegemonía creciente del mercado" (p. 117). Para este autor, el daño hecho a ese edificio de protecciones es irreversible; es por ello que enfatiza la necesidad de reestructurarlo atendiendo a las problemáticas actuales, derivadas de su desmantelamiento. En un mundo "marcado por el doble sello de la individualización y de la obligación de movilidad" (p. 120), la solución a los problemas de inseguridad que atraviesa el planeta precisa la restauración de la seguridad social (Castel, 2008). El peligro de trivializar el tema o desistir en el asunto de la seguridad social es evidente. La cosificación mercantil de la mano de obra promovida por las estrategias neoliberales afectó las condiciones de la gente asalariada al descender las protecciones laborales que caracterizaban sus empleos. Lo anterior le sirve a Castel (2008) como sustento para afirmar que "el desafío principal de la problemática de las protecciones sociales se sitúa hoy en la intersección del trabajo y del mercado" (p. 118).

Es importante señalar que Castel no promueve una postura adversa al mercado. Por el contrario, para él "no hay modernidad posible sin mercado" (2008: 119); tanto el mercado como el trabajo son los ejes centrales de la modernidad. Entonces, los cambios observados en los entornos laborales de la actualidad (flexibilidad, subcontratación, etc.) se pueden entender como experimentos derivados del propio proceso evolutivo del capitalismo; sin embargo, los resultados obtenidos hasta el momento ponen de manifiesto que tales transformaciones no son todas positivas ni representan en su totalidad alternativas viables para el largo plazo; por ello, se torna apremiante repensar

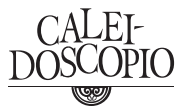


las relaciones entre mercado y trabajo, es urgente reconfigurar sus vínculos sobre cimientos de colaboración e interdependencia, no sobre nexos de dominio unidireccional.

En ese sentido, se vuelve relevante la cuestión de poner límites y desarrollar contrapesos al dominio, no necesariamente nulificar al mercado. Según Castel (2008), las conquistas alcanzadas por la sociedad salarial se desprendieron de las estrategias implementadas por los colectivos para delimitar el control ejercido por el mercado. Aunque las condiciones contextuales difieren de las de esos tiempos, "más que nunca es necesaria una instancia pública de regulación para enmarcar la anarquía de un mercado cuyo reino sin rival culminaría en una sociedad dividida entre ganadores y perdedores, ricos y miserables, incluidos y excluidos. Lo contrario de una sociedad de semejantes" (p. 119). Quien puede fungir como esta instancia sigue siendo el Estado. Se necesita la presencia de un Estado fortalecido, que reasuma dos funciones esenciales: "defender el Estado de derecho [...] y luchar contra la inseguridad social" (p. 119); un Estado social que salvaguarde el "interés general" (p. 120) por encima del provecho particular y del beneficio del sector privado. A pesar de que existe consenso sobre esto último, a los Estados actuales, en general, aún les falta mucho por resolver para convertirse en esa figura que los tiempos actuales reclaman.

\section{ENTORNOS LABORALES EN EL SIGLO XXI}

Crecer en términos económicos no ha sido suficiente. El incremento de la producción interna de un país no necesariamente implica desarrollo ni bienestar. Aunque su discurso está centrado en los países ricos de Europa, Piketty (2015) desconfía en que crecer sea la solución más adecuada para resolver los problemas económicos; mucho menos en un entorno global donde el patrimonio sigue acumulando valor a un ritmo mejor que la producción. Esto indica que la gente que históricamente ha tenido un patrimonio no tendrá que preocuparse demasiado. De manera similar a lo que sucede en otros territorios, los programas fiscales no logran solventar la injusticia acumulada por los esquemas tributarios. Los sectores privilegiados siguen viéndose favorecidos por el Estado, que recarga su expectativa de aumentar sus ingresos sobre los salarios de los sectores más austeros. 
Piketty (2015) reclama de la izquierda una postura más coherente que sirva de contrapeso a las estrategias fiscales y laborales implementadas por la derecha. De forma similar, Escalante (2015) sugiere que la izquierda ha sido asimilada por el sistema hegemónico, dejando de lado u olvidando su esencia de servir como vigilante del bienestar social en un mundo donde lo que impera es la lógica del mercado que reproduce exponencialmente la desigualdad.

La angustia es mayor en sectores socioeconómicos menos protegidos, quienes apuestan a la meritocracia de la productividad para ascender en la escala social. En lo anterior, Piketty (2015) coincide con Escalante (2015) al señalar que la desigualdad es un elemento clave en el sistema capitalista. Un sistema que en la actualidad favorece el rendimiento de los capitales por encima del rendimiento de la producción. La plusvalía de Marx se trasladó de la producción material a la esfera intangible de lo financiero. Tal vez por ello, el mercado laboral se ha ido desvalorizando, en comparación con el mercado financiero.

Siguiendo con Piketty (2015), el pueblo francés vendría padeciendo situaciones laborales similares a las observadas en México, Latinoamérica y el resto del mundo. La creación de nuevos empleos se caracteriza por su precariedad (incertidumbre, disminución de prestaciones y seguridad social, plazos cortos, facilitación del despido, etc.). Derivado de lo anterior, dos son los temas que más le preocupan: el poder adquisitivo depreciado y la incertidumbre del retiro (jubilación). El mayor costo social originado en América Latina por el hecho de disciplinarse y participar en el proceso de apertura comercial decretado por el programa neoliberal lo ha cargado sobre sus espaldas el mundo del trabajo que, según Kay (1998), "ha soportado el mayor peso de los costos sociales del ajuste" (p. 16). Es precisamente esta opresión en el ámbito laboral la que tiene empantanada a los países en vías de desarrollo; se ha convertido en una sombra que ha puesto en jaque las reformas económicas y estructurales que se intentan implantar, posicionándose como uno de los desafíos más complejos para los países de la región.

EL PERFIL JUVENIL DEL PROGRAMA NEOLIBERAL

En su más reciente libro, Fernando Escalante Gonzalbo nos presenta una historia resumida del neoliberalismo. En él, encontramos

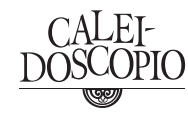


una afirmación particular elegida como hilo conductor de nuestra reflexión. Escalante (2015) considera que el programa neoliberal se caracteriza por tener rasgos tradicionalmente atribuidos a los jóvenes: rebeldes, contestatarios, disidentes, contrarios a la autoridad, descontrolados, volátiles; y que además, siguiendo al autor, son justo esos rasgos los que dotan de fortaleza y de una cierta personalidad carismática y contracultural al programa neoliberal. En esta personalidad radica tal vez la explicación de su supervivencia, dominio y continuidad de la doctrina en cuestión. A continuación, recuperamos los argumentos que Escalante utiliza para encontrar afinidades entre el programa neoliberal y la imagen de lo juvenil que emergió con fuerza a partir de las movilizaciones de los años sesenta.

En el siglo pasado, el neoliberalismo fue responsable de revitalizar gradualmente las ideas liberales, avejentadas y confrontadas por La Gran Depresión de 1929, y por el surgimiento de reacciones contrarias al sistema, como el comunismo y el fascismo. Al inicio, era una minoría la que profesaba las ideas que impulsaban la renovación liberal. Esa postura marginal fue clave en su posicionamiento como una postura rebelde, insurrecta y adversa al statu quo, "crucial para su victoria cultural de los años setenta" (Escalante, 2015: 54), años determinantes ${ }^{4}$ en la expansión mundial de la influencia del programa neoliberal.

La década de 1960 fue escenario temporal de movimientos protagonizados por jóvenes inconformes con el orden establecido. Grupos de jóvenes, en su mayoría de nacionalidad francesa, inglesa y estadounidense, organizaron movilizaciones para expresar su rechazo al autoritarismo ejercido por los adultos. Algunos rasgos comunes de esos colectivos eran su nivel académico (universitarios) y su poder adquisitivo que les posibilitaba acceder a un mundo de consumo más amplio y diverso, muy diferente al que habían conocido sus progenitores. No obstante, paradójicamente, vivían en un entorno colmado por normas que les obstaculizaba desplegar su capacidad de agencia.

4 "Los setenta fueron la década decisiva. Ahí inicia la transición cultural hacia el orden de la sociedad neoliberal. El detonador es la crisis económica, desde luego, pero contribuye también la inercia del ánimo contestatario de los sesenta, los nuevos patrones de consumo, la derecha cultural del modelo soviético, y el activismo de las fundaciones neoliberales, en conjunto, todo ello produce lo que habría que llamar un 'giro civilizatorio', que daría origen finalmente a una nueva sociedad, intensamente individualista, privatista, insolidaria, más desigual y satisfecha, conforme con esa desigualdad" (Escalante, 2015: 110-111). 
El reclamo de libertad era su motivo, y la autoridad de los adultos, su rival. El Estado, la policía, los maestros, así como toda aquella figura adulta con investidura disciplinaria, se convirtieron en los actores antagónicos más tangibles, los destinatarios naturales de la hostilidad juvenil (Escalante, 2015). Justo aquí se arraiga la idea de que las acciones del sector público son coercitivas. Idea que será capitalizada por el programa neoliberal al ofrecer un contrapeso: el ámbito privado es el camino por el que se llega a la libertad. El programa neoliberal también se resistía a la autoridad encarnada por el Estado y, al igual que los movimientos juveniles, se había embarcado en la búsqueda de la libertad. Una libertad que tiene nombre y apellido: lógica del mercado.

El espíritu de las protestas juveniles de la década de 1960 se introdujo en el cuerpo de la doctrina neoliberal. El "ánimo contestatario" (Escalante, 2015: 110), los brotes de crisis económicas en distintos territorios, el nuevo horizonte material dibujado por las posibilidades del consumo, la alarma ocasionada por las oleadas corporativistas del lado comunista del mundo y el activismo llevado a cabo por diversas fundaciones neoliberales, culminaron en una coyuntura histórica, decisiva para el advenimiento de un "giro civilizatorio" (p. 111). Una metamorfosis que engendró a la sociedad neoliberal. La genética de esa sociedad era individualista, con predilección por lo privado, poco solidaria, y bipolar en lo relacionado con la desigualdad: simpatizante, pero a la vez indiferente. A esto último, Escalante lo nombra "radicalismo ambiguo" (2015: 103).

La campaña de mercadotecnia del neoliberalismo eligió como imagen de marca ese ánimo contestatario heredado de las expresiones disidentes de los jóvenes. El "radicalismo ambiguo" (Escalante, 2015: 103) de la década de 1960 añade encanto al programa, lo vuelve más atractivo. En este sentido, el autor afirma que "había una afinidad del neoliberalismo con el ámbito radical, contestatario, de los setenta, que lo va a hacer particularmente atractivo. Es acaso la pieza clave para entender lo que viene después" (p. 99). Dicha atracción asegura que la estrategia publicitaria perdure en las próximas décadas. Por otro lado, la oposición al sistema liberal se desdibuja en la "nueva izquierda" (p. 103). La postura que antes hallaba inspiración para sus luchas en la desigualdad, muda sus malestares al terreno de los derechos humanos y al respeto a las diferencias individuales. El efecto resulta mejor de lo esperado, ya que enrola a un segmento importante de pensadores y académicos al rimar con la actitud tradicional intelectual:

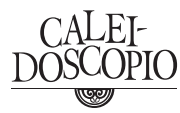


"crítica, rebelde, inconformista" (p. 304). El inventario neoliberal se diversifica. En respuesta a las señales del mercado, y con atención especial al segmento juvenil, incorpora en su catálogo: emancipación, libertad, autenticidad, autonomía, toma de decisiones, identidad. A su producto estrella le nombra "hombre nuevo", un humano "liberado de servidumbres y dependencias, que es fundamentalmente un hombre que se hace cargo de su vida y sabe asumir riesgos" (p. 166).

Por consecuencia, ofrece también la posibilidad de ser adulto: un joven emancipado. Pero ahora el rito de paso es convertirse en empresario y tener éxito. Correr riesgos, autoemplearse y emprender proyectos. El neoliberalismo también ha dado con un nuevo mesías: el empresario; creador de riqueza, bienestar y empleo. Un mesías al alcance de cualquier mortal. Sobre la figura del emprendedor revitalizada en el discurso neoliberal, Escalante (2015) nos dice que:

[... del lado positivo de la ecuación, entre los rebeldes, están los empresarios (que normalmente son también parte del establishment). El cambio cultural consiste en ponerlos simbólicamente del otro lado, con la gente menuda. En general, se emplean designaciones amables e incluso encomiásticas: son los creadores de riqueza o los creadores de empleo. Pero no es lo fundamental, sino la idea de que todos somos empresarios, como dirían Becker o de Soto, o que todos seríamos empresarios si no estuviésemos oprimidos por un Estado que nos lo impide (p. 304).

Es por ello, tal vez, que el profesor aliado del sistema neoliberal es el que enseña a ingresar al mundo del emprendizaje, sólo se requiere aprobar los cursos obligatorios de: flexibilidad, precariedad y competitividad. No hay mejor docente que aquel que utiliza la "pedagogía de la miseria" (p. 167). El paquete armado de rebeldía y riqueza ha dejado buenos dividendos; ${ }^{5}$ para el autor, "el neoliberalismo capitaliza el prestigio de la rebelión a la vez que desculpabiliza la riqueza" (p. 304). Además, entre sus secuelas, ha creado una figura fabulosa: el consumidor que, para mantener su membresía en el club de la libertad, ha de aceptar convertirse, ya sea en mesías o en esclavo laboral del proveedor que se la otorga. El sistema termina ganando en ambos casos.

5 Según Escalante (2015: 304), “el neoliberalismo capitaliza el prestigio de la rebelión a la vez que desculpabiliza la riqueza". 
El hechizo continúa. Los años de 1990 y el arranque del nuevo siglo siguen con la camiseta neoliberal bien puesta. Hay un fenómeno global de índole financiero que eclosiona, una evidencia que no deja lugar a dudas de la potente alquimia neoliberal. El neoliberalismo procrea la crisis del 2008, pero guarda silencio, se esconde. Le adjudica la paternidad al Estado, que no se atreve a negarla. Desorientado y falto de alternativas, sale al rescate del padre biológico. El rescate suntuario se compensa con planes de austeridad en el gasto público. En el imaginario social, el Estado es el único culpable, continúa el desprestigio, su reputación a la baja. Sigue siendo el malo del cuento, el enemigo del pueblo. El neoliberalismo palpa su mayor victoria: ha colonizado el sentido común (Escalante, 2015); reacción inesperada, pero aprovechada por el programa. La solución gastada del mercado es presentada como novedad. El mercado es un tianguis simbólico, aquí se hallan a precios competitivos y a meses sin intereses las utopías que el Estado no pudo fabricar: "felicidad, crecimiento, bienestar, estabilidad" (p. 313). El neoliberalismo toma aire, respira, se recupera, se rehace, se adapta, se reorganiza. Reafirma su identidad libertaria, revolucionaria, divergente. Aún más, se dogmatiza: "sigue siendo joven, rebelde, iconoclasta, científico, realista, esperanzador" (p. 301). Su mercado cautivo aumenta. A los jóvenes les vende promesas de independencia, expresión y consumo virtual, ilusiones de futuro. Les ha diseñado tres planes a la medida: emprendizaje, desempleo o empleos flexibles, sin jubilaciones ni pensiones, ni seguridad social. Clausura los planes a futuro. A cambio les seduce con aplicaciones, autorretratos digitales y con la idea de vivir al máximo, un día a la vez. Los dueños del capital proclaman haber encontrado el elixir de la juventud eterna, por lo que se prevé que en sus planes de expansión de mercados está descontinuar la adultez. O mejor, diseñar un híbrido que incorpora lo mejor de ambos mundos: el "adultescente" (Feixa, 2014; Feixa y Fernández-Planells, 2014; Juris, Pereira y Feixa, 2012).

\section{CONCLUSIONES}

Uno de los aspectos señalados con mayor frecuencia en los análisis que se hacen sobre jóvenes latinoamericanos es la insuficiencia de oportunidades laborales dignas, situación que dificulta su transición a la vida adulta. De acuerdo con los estudios analizados, la independen-

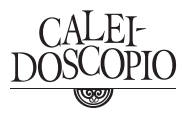


cia económica del núcleo familiar parental se ha vuelto cada vez más difícil de conseguir; la precariedad laboral que caracteriza el mundo del trabajo en el siglo XXI ha ralentizado la llegada a la etapa adulta, tal y como esta última se había entendido en el pasado.

El desencanto de la vida adulta se puede comprender como un derivado de la crisis de la modernidad. Recordemos que ésta incorporaba en su proyecto diferentes promesas que debían cumplirse al dejar atrás la juventud: prosperidad, movilidad social, libertad, estabilidad, progreso y la opción del retiro laboral bajo el resguardo de una pensión que permitiera vivir una vejez tranquila, aguardaban a quienes se emanciparan de sus familias; es decir, a los adultos. Junto con la edad adulta, los postulados de la modernidad han perdido fuerza, dando paso a nuevos desafíos y problemas y, por lo tanto, han surgido diferentes formas de existir y pensarse en el mundo. Condiciones laborales precarias, inciertas e inseguras signan múltiples trayectorias humanas, independientemente de la edad que se tenga; lo cual desencadena que un gran segmento de la población parezca destinado a permanecer en condiciones concebidas antaño como propias de la juventud: inestabilidad e incertidumbre.

La extensión mundial del programa neoliberal, junto con los avances tecnológicos, han originado alteraciones en las actividades económicas, así como cambios en las relaciones entre individuos y mundo del trabajo formal. El incremento poblacional crece a un ritmo mayor que la generación de oportunidades laborales. Las empresas han optado por fragmentar y trasladar sus actividades productivas a países -principalmente subdesarrollados-, donde hay exceso de mano de obra; esto propicia que el salario sea uno de los factores clave para reducir costos y aumentar posibilidades de competir con éxito en los mercados nacionales o internacionales.

Dicha estrategia competitiva, asumida por el sector empresarial y avalada por el Estado, ha ocasionado fenómenos como el de flexibilidad o precarización laboral, los cuales implican estancamiento o reducción del poder adquisitivo del salario y pérdida gradual de ciertos derechos o incentivos laborales conquistados con anterioridad. La flexibilización también ha impactado directamente en la relación contractual que une al trabajador con su empleador. En muchos casos, el contrato ha dejado de ser por tiempo indefinido; ha cambiado su duración a plazos específicos (por lo general son contratos de pocos meses). En otras palabras, el contrato ha dejado de representar certe- 
za laboral de largo plazo, lo cual afecta también al resto de proyectos de largo aliento de los individuos.

El programa neoliberal es resistente. Las movilizaciones sociales no lo tocan, las adversidades las sortea, las críticas lo alimentan. Tanto las juventudes asimiladas o las disidentes lo nutren, lo revitalizan y le brindan nuevas ideas. Le ayudan a crear nuevos mercados que prometen la resolución más eficiente a sus demandas. Este andamiaje económico es resiliente, supera las dificultades y al mismo tiempo se fortalece.

El neoliberalismo tiene un saldo deudor con los jóvenes. Como hemos visto, su doctrina se ha inspirado en la creatividad juvenil, en sus expresiones, en sus demandas. Pero no les ha pagado con justas regalías. Las regalías con las que les compensa son membresías VIP al mundo del consumo, palcos en Internet y zonas preferentes en redes sociales virtuales. Les retribuye con desempleo y precariedad; también con juventud perenne: postergación indefinida de la adultez.

A manera de cierre optimista, queremos resaltar que, con sus nuevos repertorios, las movilizaciones juveniles recientes intentan resarcir el involuntario daño que, según el argumento de Escalante (2015), algunas conquistas de las generaciones jóvenes de antaño provocaron al ser distorsionadas por la lógica del mercado. Esperamos que logren rotar, aunque sea algunos grados, el eje neoliberal. Tal vez los mandamientos del programa no se alteren del todo, pero puede ser que emerja y prevalezca en el tiempo una inercia de mercado diferente, con personalidad distinta. Una personalidad que conserve su aire disidente, pero que sea menos rapaz, menos austera, menos competitiva, más comunitaria. Una forma de ser que incorpore en su temperamento rasgos de reciprocidad, justicia y solidaridad; cualidades que ayuden a templar su carácter. En fin, permanece la esperanza de que reconozca su lado femenino y desplace al sistema patriarcal que le dio origen; que sea tan sensible como racional, para que sea capaz de intuir, leer y ser empática con las señales de los movimientos nacidos desde abajo; que les aprenda, les honre y, por supuesto, les compense de manera justa.






\section{REFERENCIAS}

Castel, R. (2008). La inseguridad social: ¿qué es estar protegido? Buenos Aires: Manantial.

CEPAL. (2008). Juventud y cohesión social en Iberoamérica. Un modelo para armar. Santiago: Comisión Económica para América Latina y el Caribe. Recuperado de: http://repositorio.cepal.org/handle/1 1362/3639.

CEPAL y OIJ. (2007) La juventud en Iberoamérica: Tendencias y urgencias. Santiago: Comisión Económica para América Latina y el Caribe; Organización Iberoamericana de Juventud. Recuperado de: http://repositorio.cepal.org/handle/11362/2785.

Contreras, M. (2015). Crítica a la razón neoliberal. Del neoliberalismo al posliberalismo. México, D.F.: Akal.

Dallanegra, L. (2015). Teoría y metodología de la geopolítica. Hacia una geopolítica de la "construcción del poder". Revista Mexicana de Ciencias Políticas y Sociales, 52(210), 15-42. Recuperado de: http:// www.redalyc.org/articulo.oa?id=42118500002.

Escalante, F. (2015). Historia mínima del neoliberalismo. México, D.F.: El Colegio de México.

Feixa, C. (2006). Generación XX. Teorías sobre la juventud en la era contemporánea. Revista Latinoamericana de Ciencias Sociales, Niñez y Juventud, 4(2), 2-18. Recuperado de: http://www.scielo.org.co/scielo. php?script=sci_arttextEpid=S1692-715X2006000200002.

Feixa, C. (2014). De la generación @ a la \#Generación. La juventud en la era digital. Barcelona: Ned Ediciones.

Feixa, C. y Fernández-Planells, A. (2014). Generación @ versus Generación \#. La juventud en la era hiperdigital. En A. Huertas y M. Figueras (Eds.). Audiencias juveniles y cultura digital (pp. 35-54). Bellaterra: Institut de la Comunicació, Universitat Autònoma de Barcelona. Recuperado de: http://incom.uab.es/download/eBook_ InComUAB_audienciajuvenilculturadigital.pdf.

García Canclini, N. y Piedras, E. (2013). Jóvenes creativos. Estrategias y redes culturales. México, D.F.: Universidad Autónoma Metropolitana, Unidad Iztapalapa; Juan Pablos Editor.

Gómez, M. (2012). Los jóvenes ante la precariedad laboral. En M. L. Jiménez y R. Boso (Coords.). Juventud precarizada. De la formación al trabajo, una transición riesgosa (pp. 25-46). Cuernavaca: UnAM, Centro Regional de Investigaciones Multidisciplinarias. 
Juris, J., Pereira, I. y Feixa, C. (2012). La globalización alternativa y los 'novísimos' movimientos sociales. Revista del Centro de Investigación. Universidad La Salle, 10(37), 23-39. Recuperado de: http://www.redalyc.org/articulo.oa?id=34223328002.

Kay, C. (1998). Estructuralismo y teoría de la dependencia en el periodo neoliberal: una perspectiva latinoamericana. Nueva Sociedad, (158), 100-119. Recuperado de: http://nuso.org/media/articles/ downloads/2728_1.pdf.

Levi, G. y Schmitt, J. C. (1996). Historia de los jóvenes I. De la Antigüedad a la Edad Moderna. Madrid: Taurus.

Martínez, R. y Soto, E. (2012). El Consenso de Washington: la instauración de las políticas neoliberales en América Latina. Política y Cultura, (37), 35-64. Recuperado de: https://bit.ly/2EevyxV.

Piketty, T. (2015). La crisis del capital en el siglo XXI: crónicas de los años en que el capitalismo se volvió loco. México, D.F.: Siglo XXI.

Revilla, J. C. (2001). La construcción discursiva de la juventud: lo general y lo particular. Papers, 63/64, 102-122. DOI:10.5565/rev/papers/ v63n0.1209.

Verd, J. M. y López-Andreu, M. (2016). Crisis del empleo y polarización de las trayectorias laborales. El caso de los adultos jóvenes en Cataluña. Papers, 101, 5-30. DOI: 10.5565/rev/papers.2167.

ACERCA DE LA AUTORA

Olga Leticia Álvarez Cooper (llqper@gmail.com) es licenciada en Comercio Exterior por la Facultad de Economía de la UASLP, magíster en Educación por la Universidad del Centro de México. Docente de educación superior en varias instituciones públicas y privadas de la ciudad de San Luis Potosí. Doctorante del Programa de Estudios Latinoamericanos en Territorio, Sociedad y Cultura de la UASLP, becaria CONACYT (ORCID 0000-0003-1909-7431).

\section{CÓMO CITAR ESTE ARTÍCULO}

Álvarez, O. (2018). Jóvenes, trabajo y emancipación: llaga neoliberal de nuestro tiempo. Caleidoscopio. Revista Semestral de Ciencias Sociales y Humanidades, 22(39). DOI: 10.33064/39crscsh 1488 
